\title{
Chamomile Flower Oil
}

National Cancer Institute

\section{Source}

National Cancer Institute. Chamomile Flower Oil. NCI Thesaurus. Code C74287.

The essential oil extracted from the flowers of Anthemis nobilis or Matricaria chamomilla.

Chamomile oil is used in various preparations for calming and relaxing effects, especially on the nervous and digestive systems. 